\title{
A Volatile Ethylene Inhibitor Improves the Postharvest Life of Potted Roses
}

\author{
Margrethe Serek ${ }^{1}$ and Michael S. Reid \\ Department of Environmental Horticulture, University of California, Davis, CA 95616
}

Edward C. Sisler

Department of Biochemistry, North Carolina State University, Raleigh, NC 2769

Additional index words. bud abscission, DACP, ethylene binding, flower senescence, STS

\begin{abstract}
Pretreating 'Victory Parade' potted miniature roses (Rosa hybrida L.) with photolyzed diazocyclopentadiene (DACP) inhibited the effects of exogenous ethylene (acceleration of leaf and bud drop). In an ethylene-free simulated interior environment, display life of the treated plants was also greater than that of the controls and similar to that of plants pretreated with the anionic silver thiosulfate complex (STS). DACP caused an increase in the binding constant for ethylene in petals and leaves of 'Victory Parade' and 'Cara Mia' (a cut-flower rose cultivar). Competitive kinetics for the effects of increasing ethylene concentrations on control and DACP-treated plants are consistent with the hypothesis that the effects of DACP are due to irreversible binding to the ethylene-binding site.
\end{abstract}

The quality and display life of potted flowering plants are often reduced by the effects of ethylene in the environment or physiological effects, such as leaf drop, bud abortion, and bud abscission, that are attributed to ethylene (Reid, 1985; Reid and Wu, 1992). Improved quality has been achieved by spraying plants with cytokinins (Halevy and Kofranek, 1976; Serek and Andersen, 1993), which reduce ethylene sensitivity (Zacarias and Reid, 1990), or with the anionic silver thiosulfate complex (STS). This latter technique is now in widespread commercial use (Nowak and Rudnicki, 1990), but has been criticized on environmental grounds. The use of a heavy-metal salt in horticulture will always be a matter for concern, and we have continued to search for alternatives to STS for overcoming ethylene-related problems. Sisler and Blankenship (1993) reported the ethylene antagonism of diazocyclopentadiene (DACP), a putative photoaffinity label for the ethylene-binding site. This volatile compound has increased the life of cut carnations (Sisler et al., 1993), and we report here a study of its effects on potted flowering crops, for which its volatility would be a major practical advantage. The pronounced beneficial effects of DACP on potted roses that we observed prompted us to investigate its mode of action in more detail, and we report its effects on ethylene binding in potted roses and in a commercial cut-flower rose cultivar.

\section{Materials and Methods}

Plant material. Four-inch potted flowering plants of Rosa hybrida 'Victory Parade' were obtained from a commercial grower at the bud stage and transported to the Univ. of California, Davis. The plants were finished in a growth chamber under the following conditions: $22 \mathrm{C}, 80 \mu \mathrm{mol} \cdot \mathrm{m}^{-2} \cdot \mathrm{s}^{-1}$ from 0200 to $2300 \mathrm{HR}$, and $90 \%$

Received for publication 4 June 1993. Accepted for publication 14 Sept. 1993. We thank F. Jackson Hills, Peggy Hale, and Carol Adams for advice on data analysis, Linda Dodge for technical assistance, and Nurserymen's Exchange, Half Moon Bay, for kindly supplying the plants. The experiments were supported by a grant from the Danish Agricultural and Veterinary Research Council (grant no. 13-4549) and supplementary grants from the Foundation of Hofmansgave, the Foundation of Ib Henriksen and the Carlsberg Foundation (MS). The cost of publishing this paper was defrayed in part by the payment of page charges. Under postal regulations, this paper therefore must be hereby marked advertisement solely to indicate this fact. ${ }^{1}$ Permanent address: The Royal Veterinary and Agricultural Univ., Section for Horticulture, Rolighedsvej 23, 1958 Frederiksberg C., Denmark. To whom reprint requests should be addressed. relative humidity (RH). At commercial maturity (three to five fully open flowers per plant), the plants were treated with DACP or STS. For ethylene-binding experiments, similar plants or commercially harvested flowers of Rosa hybrida 'Cara Mia' were air-freighted to North Carolina, where they were used immediately.

$D A C P$ treatment. Plants were placed in sealed glass chambers at $20 \mathrm{C}$, and calculated aliquots of a $9 \%$ solution of DACP in pentane were placed on filter papers inside the chamber. The pentane was without effect if DACP was not present. All DACP values are reported as initial gas-phase concentrations of DACP in $\mu \mathrm{l} \cdot$ liter $^{-1}$. The chambers remained sealed for $24 \mathrm{~h}$ and were constantly illuminated with light $\left(70 \mu \mathrm{mol} \cdot \mathrm{m}^{-2} \cdot \mathrm{s}^{-1}\right)$ from cool-white fluorescent tubes (ACME, Los Angeles). Treated plants were then exposed to ethylene (at 20C) or placed in the interior environment for evaluation of shelf life.

STS treatment. Plants were sprayed $(25 \mathrm{ml} / \mathrm{plant})$ with a commercial STS solution (Argylene APS, Denmark) containing 0.2 mM STS. Control and STS-treated plants were held for $24 \mathrm{~h}$ in a sealed glass chamber with supplementary light, as for the DACP-treated plants, before being exposed to ethylene or placed in the interior environment for evaluation of shelf life.

Ethylene treatment. After DACP and STS treatments, $50 \%$ of the plants was enclosed for 7 days in glass chambers ventilated ( 40 liters $\cdot \mathrm{h}^{-1}$ ) with air containing $0.6 \mu \mathrm{l} \cdot \mathrm{liter}^{-1}$ of ethylene gas. The ethylene concentration was monitored daily by gas chromatography. Leaf and bud drop were recorded.

To examine the inhibitory action of DACP further, treated plants $\left(1 \mu \mathrm{l} \cdot\right.$ liter $\left.^{-1} \mathrm{DACP}\right)$ were placed in glass chambers ventilated (40 liters $\cdot \mathrm{h}^{-1}$ ) with air containing various concentrations of ethylene gas. Leaf and bud drop was evaluated daily.

Evaluation in the interior environment. To evaluate commercial shelf life, treated plants were placed in a simulated interior environment at $20 \mathrm{C}, 60 \% \mathrm{RH}$, and $12 \mathrm{~h}$ per day of light $(15$ $\mu \mathrm{mol} \cdot \mathrm{m}^{-2} \cdot \mathrm{s}^{-1}$ ) from cool-white fluorescent tubes. Bud drop, flower number per plant, and the longevity of individual flowers were recorded daily.

Binding assays. Petals or leaves were removed from the plant and allowed to stand overnight for wound ethylene to subside. Binding assays were carried out with $2 \mathrm{~g}$ miniature rose petals (5 $\mathrm{g}$ of 'Cara Mia' petals) or $2 \mathrm{~g}$ miniature rose leaves (7 $\mathrm{g}$ of 'Cara Mia' leaves). Samples were exposed to $0.5 \mu \mathrm{Ci}$ of ${ }^{14} \mathrm{C}$-ethylene and $\mathrm{DACP}$ in 2.5-liter desiccators for $3 \mathrm{~h}$. Other samples were vented 
for either 30 or $45 \mathrm{sec}$. Samples were then placed in jars containing vials of mercuric perchlorate $(0.3 \mathrm{ml}$ on a $2 \times 2-\mathrm{cm}$ piece of fiberglass filter) for at least $12 \mathrm{~h}$ to collect the labeled ethylene present in the tissue. Scintillation fluid was then added to the vials and the radioactivity of the trapping solution was determined.

\section{Results}

Effects of DACP, STS, and ethylene. Untreated miniature rose plants exposed to $0.6 \mu \mathrm{l} \cdot$ liter $^{-1}$ ethylene rapidly lost leaves and buds (Fig. 1 a and b). Within 3 days of the initiation of ethylene treatment, most of the buds and nearly all of the leaves had abscised

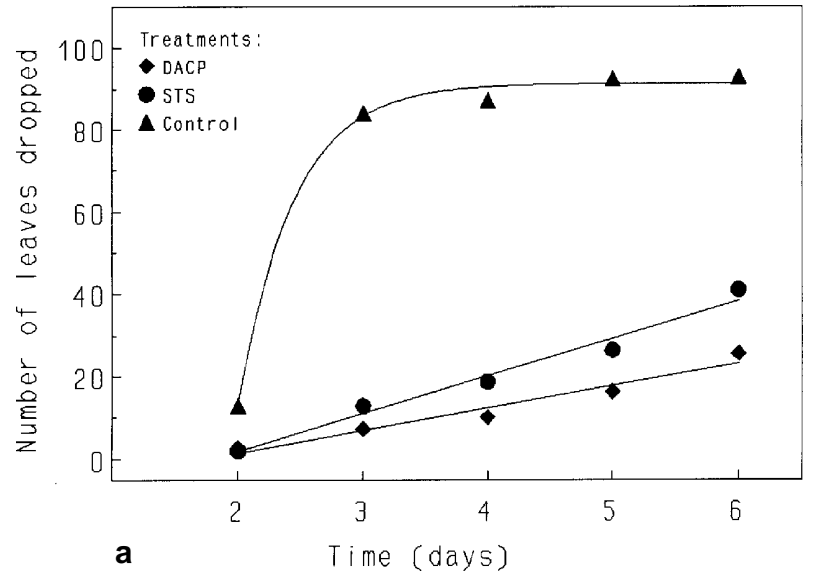

(Fig. 2). Few open flowers abscised. Pretreating the plants with 0.2 mM STS or $1 \mu \mathrm{l} \cdot$ liter $^{-1}$ DACP strongly inhibited the effects of ethylene on leaf drop and bud abscission. DACP was significantly better than STS in preventing ethylene-mediated leaf drop. There was no difference in ethylene-mediated bud drop between these two treatments.

Effects on display life. In the interior environment, plants that had been pretreated with DACP and STS had a much improved shelf life, even in the absence of exogenous ethylene. Bud drop in the treated plants was $\approx 50 \%$ less than that in the untreated plants (Fig. 3). This resulted in a significant increase in the number of open flowers per plant (Fig. 4). The longevity of individual

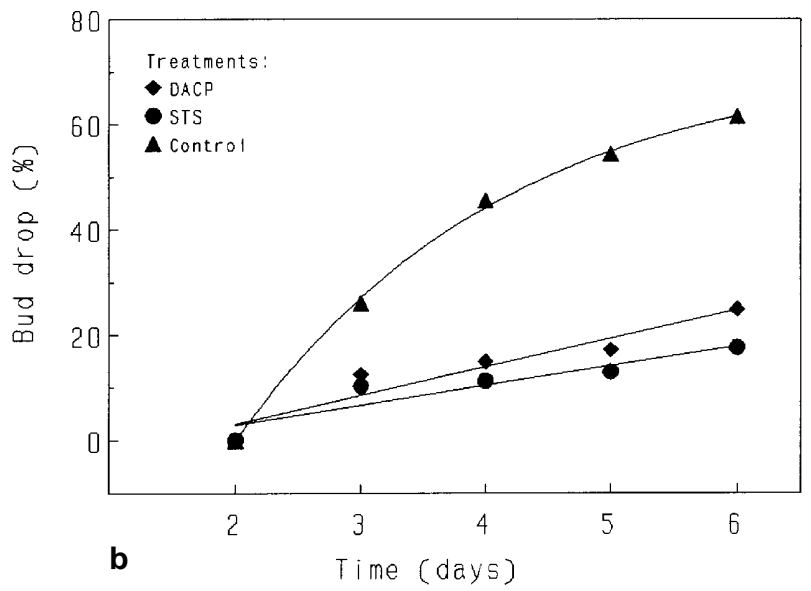

Fig. 1. Ethylene-stimulated leaf drop (a) and bud drop (b) in plants of Rosa hybrida 'Victory Parade' pretreated with $1 \mu 1 \cdot$ liter ${ }^{-1}$ DACP or 0.2 mM STS. Control plants were placed, in air, in identical tanks to those used for DACP treatment. After treatment, all plants were exposed to $0.6 \mu 1 \cdot$ liter $^{-1}$ ethylene for 7 days.

Source of variation:

Treatment:

Days:

Control vs. others

DACP vs. STS

Linear

Quadratic

Treatment $\times$ days: $\quad$ Control vs. others $\times$ linear

DACP vs. STS $\times$ linear

Control vs. others $\times$ quadratic

DACP vs. STS $\times$ quadratic

$\begin{array}{ll}\mathbf{a} & \mathbf{b} \\ * * * & * * * \\ * & \mathrm{NS} \\ * * * & * * * \\ * * * & * * * \\ * * * & * * * \\ * * & \mathrm{NS} \\ * * * & * * \\ \mathrm{NS} & \mathrm{NS}\end{array}$

${ }_{\mathrm{Ns}, *, * *, * * * *}$ Nonsignificant or significant at $P=0.05,0.01$, or 0.001 , respectively,

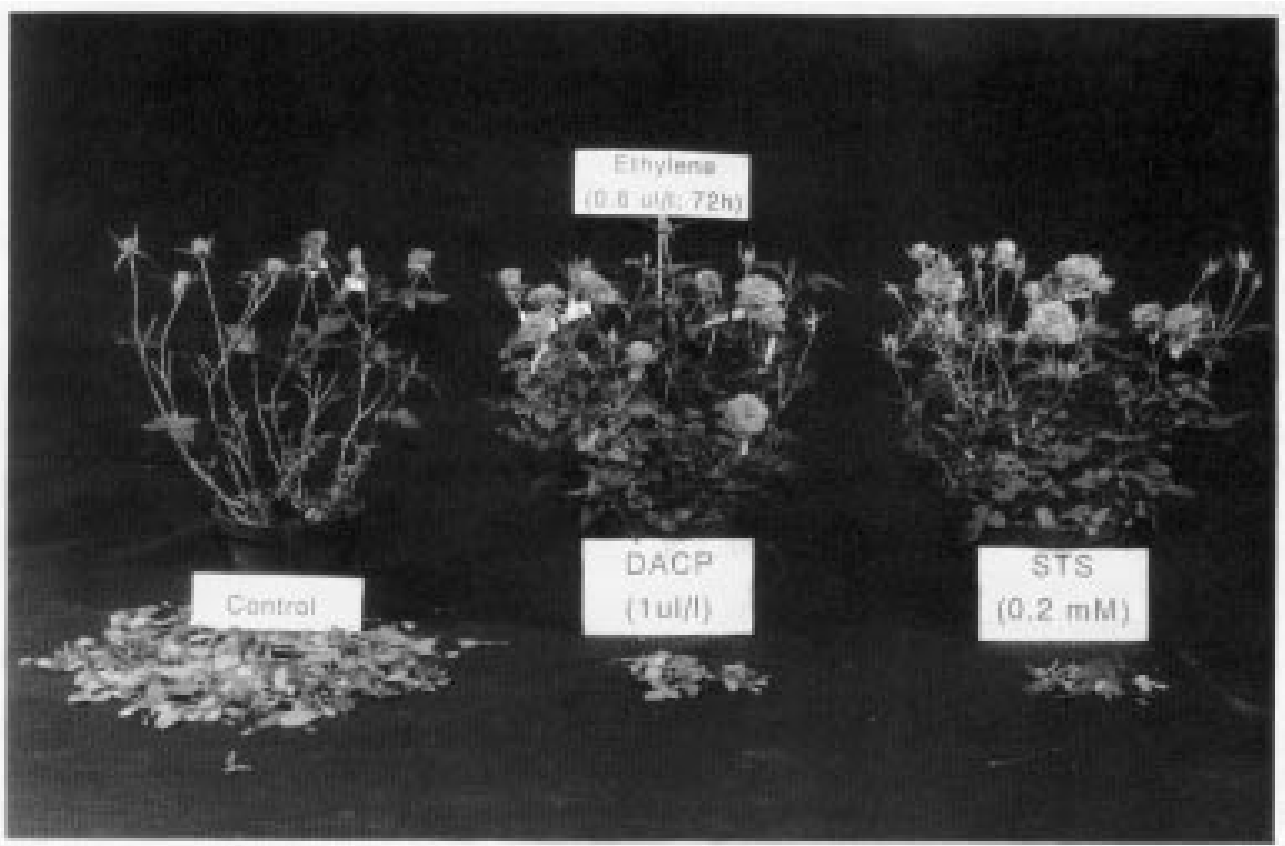

Fig. 2. Leaf drop in plants of Rosa hybrida 'Victory Parade' treated with $1 \mu 1 \cdot$ liter $^{-1}$ DACP or 0.2 mm STS after exposure for 3 days to $0.6 \mu 1$-liter ${ }^{-1}$ ethylene. Control plants were placed, in air, in identical tanks to those used for the DACP treatment. 


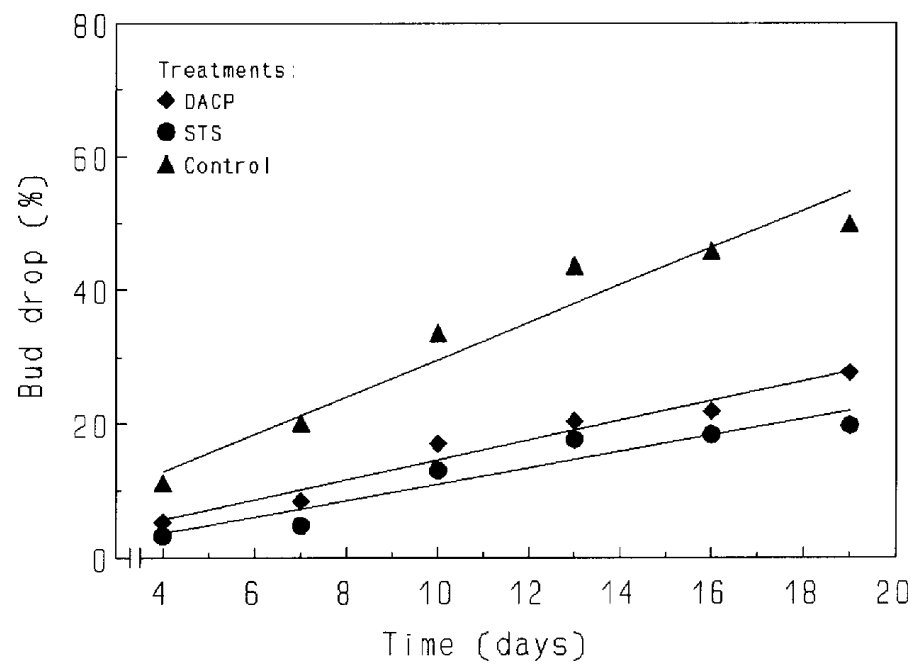

Fig. 3. Bud drop (\%) per plant in Rosa hybrida 'Victory Parade' plants treated with $1 \mu \mathrm{l} \cdot$ liter $^{-1}$ DACP or 0.2 mm STS. Control plants were placed, in air, in identical tanks to those used for the DACP treatment. After treatment, plants were kept in an interior environment.

Source of variation:

Control vs. others

DACP vs. STS

Days:

Linear

Quadratic

Treatment $\times$ days: $\quad$ Control vs. others $\times$ linear

DACP vs. STS $\times$ linear

Control vs. others $\times$ quadratic

DACP vs. STS $\times$ quadratic

Ns,***** Nonsignificant or significant at $P=0.05$ or 0.001 , respectively.

flowers, whether open or buds showing color at the time of treatment, was increased equally by DACP and STS (Table 1). Flowers that had opened in the greenhouse had greater longevity than those that opened in the interior environment. No differences among treatments were observed with relation to leaf abscission (data not shown).

Effects of DACP concentration. Treating plants with different concentrations of DACP resulted in a wide range of responses to applied ethylene (Fig. $5 \mathrm{a}$ and b). Treatment with 1 or $2 \mu \mathrm{l} \cdot \mathrm{liter}^{-1}$ essentially eliminated ethylene-stimulated bud and leaf drop over the 6 days of ethylene treatment. At lower concentrations, the inhibitory effect was less marked. The time course of abscission in control plants was different for the two organs, being very rapid for leaves and more gradual for buds.

Effects of ethylene concentration. The effects of ethylene concentration on the ability of $1 \mu \mathrm{l} \cdot$ liter $^{-1}$ DACP to prevent ethylene action are shown in Fig. 6. Even low concentrations of ethylene stimulated leaf drop in these rose plants (Fig. 6a), and, in 1 $\mu l \cdot$ liter $^{-1}$ ethylene, the plants were essentially defoliated after 4 days. DACP was most effective for plants receiving low concentrations of ethylene, but even at $1 \mu \mathrm{l} \cdot$ liter $^{-1}$ ethylene, the inhibitor markedly reduced abscission (Fig. 6b). The data for the effect of different ethylene concentrations on inhibition of leaf drop by DACP at 2 days are plotted as a double-reciprocal graph in Fig. 7. The lines intersect close to the ordinate axis, which would be interpreted as noncompetitive inhibition if the observed effects are the result of a single ligand-protein interaction.

Ethylene binding. Measurements of displacement of radioactive ethylene from its binding site by different concentrations of unlabeled DACP can be plotted as scatchard plots (Fig. 8) whose slope indicates the binding affinity for DACP $(\mathrm{Kd})$. Calculated binding constants $(\mathrm{Kd})$ for DACP of petals and leaves of miniature

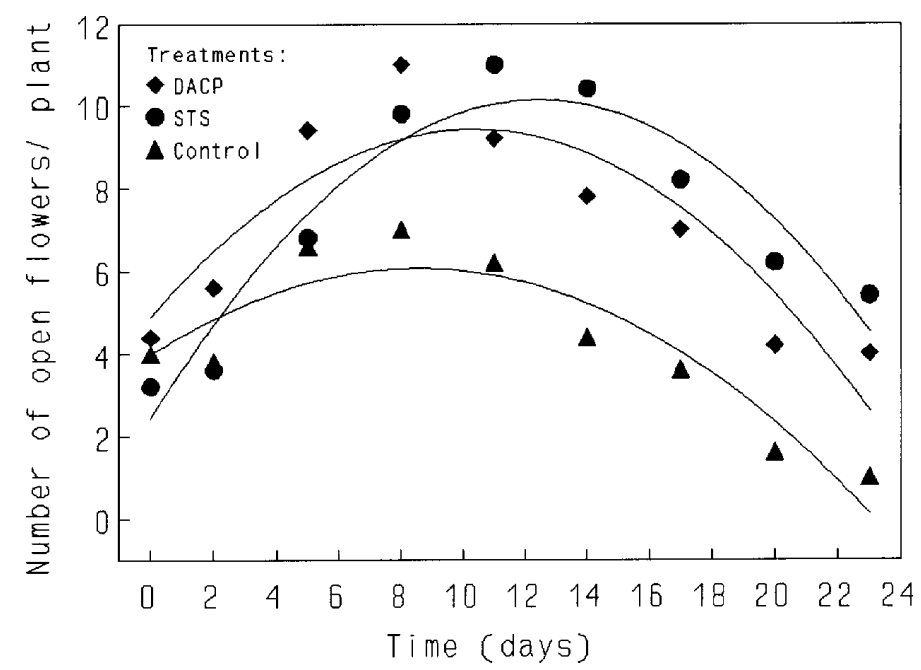

Fig. 4. Number of open flowers per plant in Rosa hybrida 'Victory Parade' treated with $1 \mu l \cdot$ liter $^{-1}$ DACP or $0.2 \mathrm{~mm}$ STS. Control plants were placed, in air, in identical tanks to those used for the DACP treatment. After treatment, plants were kept in the interior environment room.

Source of variation:

Treatment:

Control vs. others

Days:

DACP vs. STS

Quadratic

Treatment $\times$ days:

Control vs. others $\times$ linear

DACP vs. STS $\times$ linear

Control vs. others $\times$ quadratic

DACP vs. STS $\times$ quadratic

***

$* * *$

$* *$

NS

NS

Nonsignificant or significant at $P=0.05,0.01$ or 0.001 , respectively.

Table 1. Longevity of individual flowers treated in open-flower stage or bud showing color stages with DACP, STS, or air before placement in the interior environment.

\begin{tabular}{lcc}
\hline & \multicolumn{2}{c}{ Flower longevity (days) } \\
\cline { 2 - 3 } Treatment & $\begin{array}{c}\text { Open-flower } \\
\text { treated }\end{array}$ & $\begin{array}{c}\text { Bud } \\
\text { treated }\end{array}$ \\
\hline DACP & 18.5 & 11.5 \\
STS & 18.2 & 12.7 \\
Control & 15.4 & 9.6 \\
Contrast & & $*$ \\
Control vs. others & $*$ & $\mathrm{NS}$ \\
DACP vs. STS & $\mathrm{NS}$ &
\end{tabular}

Ns, ${ }^{*}$ Nonsignificant or significant at $P=0.05$, respectively.

and cut-flower rose cultivars were substantially higher than for ethylene (Table 2). The concentration of light-activated DACP needed to prevent ethylene binding (Table 2) compares favorably with the concentration of DACP needed to prevent a physiological response (Fig. $5 \mathrm{a}$ and b) to ethylene. This suggests it is the lightgenerated product that is important.

\section{Discussion}

The postharvest life of many flowering potted plants is terminated, as for the miniature roses used in this study, by bud abscission and flower fading. When the handling or display environment is contaminated with ethylene, these events can be greatly accelerated. Although STS is now widely used to reduce these problems, environmental concerns have restricted its application in some countries. The search for other inhibitors of ethylene action has concentrated recently on ethylene analogs. 

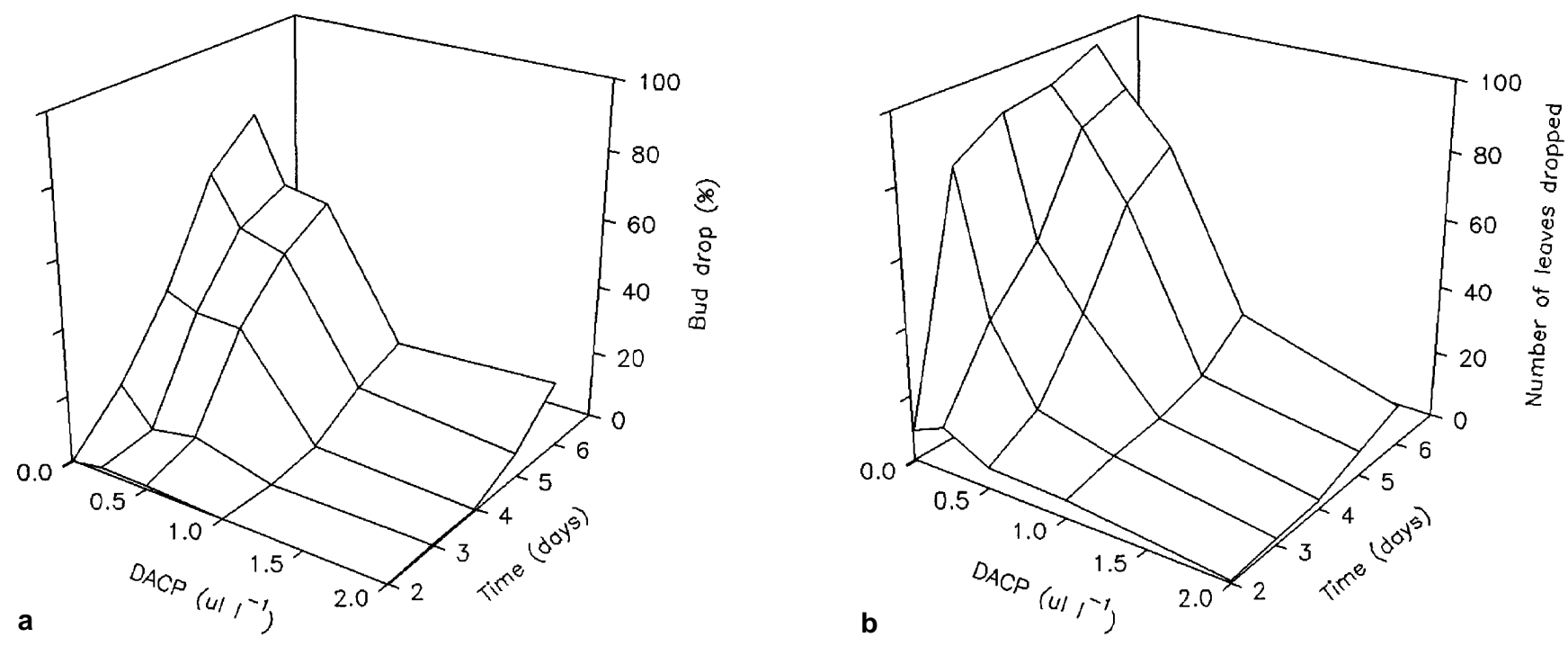

Fig. 5. Ethylene-stimulated bud drop (a) and leaf drop (b) in plants of Rosa hybrida 'Victory Parade' pretreated with $0,0.2,0.5,1.0$, or $2.0 \mu 1 \cdot$ liter ${ }^{-1} \mathrm{DACP}$. Control plants were placed, in air, in identical tanks to those used for the DACP treatment. After treatment, all plants were exposed to $0.6 \mu l \cdot l i t e{ }^{-1}$ ethylene for 6 days.

Source of variation:

Treatment:

0 DACP (control) vs. others

1.0 DACP vs. 2.0 DACP

1.0 DACP vs. 0.5 DACP

Days:

Linear

Quadratic

Treatment $\times$ days: $\quad 0$ DACP (control) vs. others $\times$ linear

1.0 DACP vs. 2.0 DACP $\times$ linear

1.0 DACP vs. 0.5 DACP $\times$ linear

0 DACP (control) vs. others $\times$ quadratic

1.0 DACP vs. 2.0 DACP $\times$ quadratic

1.0 DACP vs. $0.5 \mathrm{DACP} \times$ quadratic

Ns,******Nonsignificant or significant at $P=0.01$ or 0.001 , respectively.

$\begin{array}{ll}\mathbf{a} & \mathbf{b} \\ * * & * * * \\ \mathrm{NS} & \mathrm{NS} \\ * * & * * \\ * * * & * * * \\ \mathrm{NS} & * * * \\ * * * & * * * \\ \mathrm{NS} & \mathrm{NS} \\ * * * & * * * \\ \mathrm{NS} & * * * \\ \mathrm{NS} & \mathrm{NS} \\ \mathrm{NS} & \mathrm{NS}\end{array}$

NS
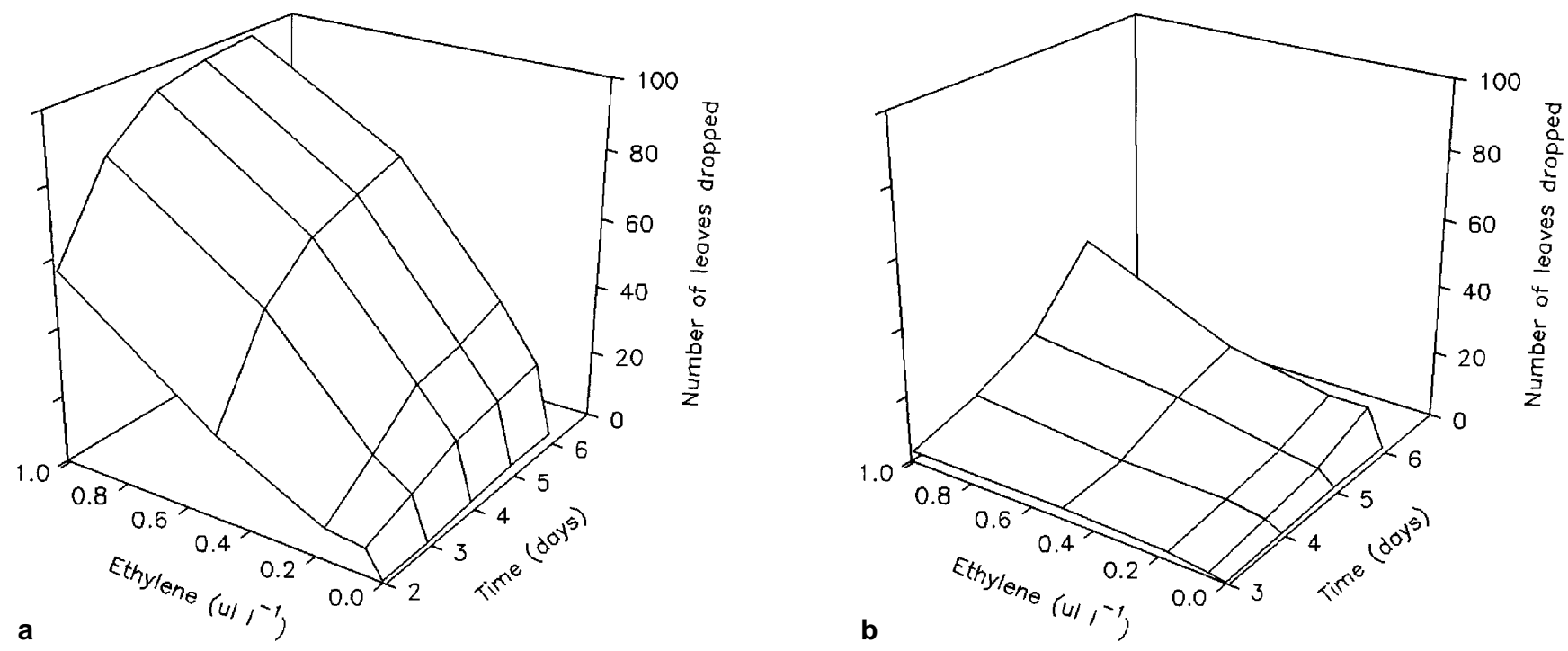

Fig. 6. Ethylene-stimulated leaf drop in plants of Rosa hybrida 'Victory Parade' pretreated with $1 \mu 1 \cdot 1$ liter-1 DACP (b). Control plants (a) were placed, in air, in identical tanks to those used for DACP treatment. After treatment, all plants were exposed to $0,0.05,0.17,0.5$, or $1.0 \mu 1 \cdot$ liter $^{-1}$ ethylene for 6 days.

Source of variation:

Treatment:

0 Ethylene (control) vs. others

Among ethylene

Days:

Linear

Quadratic

Treatment $\times$ days:

0 eth (control) vs. others $\times$ linear

Among ethylene $\times$ linear

0 eth (control) vs. others $\times$ quadratic

Among ethylene $\times$ quadratic

ss,*******Nonsignificant or significant at $P=0.01$ or 0.001 , respectively.

$\begin{array}{ll}\mathbf{a} & \mathbf{b} \\ * * & * * * \\ * * & * * * \\ * * * & * * * \\ * * & * * * \\ * * * & * * * \\ * * * & * * * \\ \mathrm{NS} & * * * \\ \mathrm{NS} & * * *\end{array}$




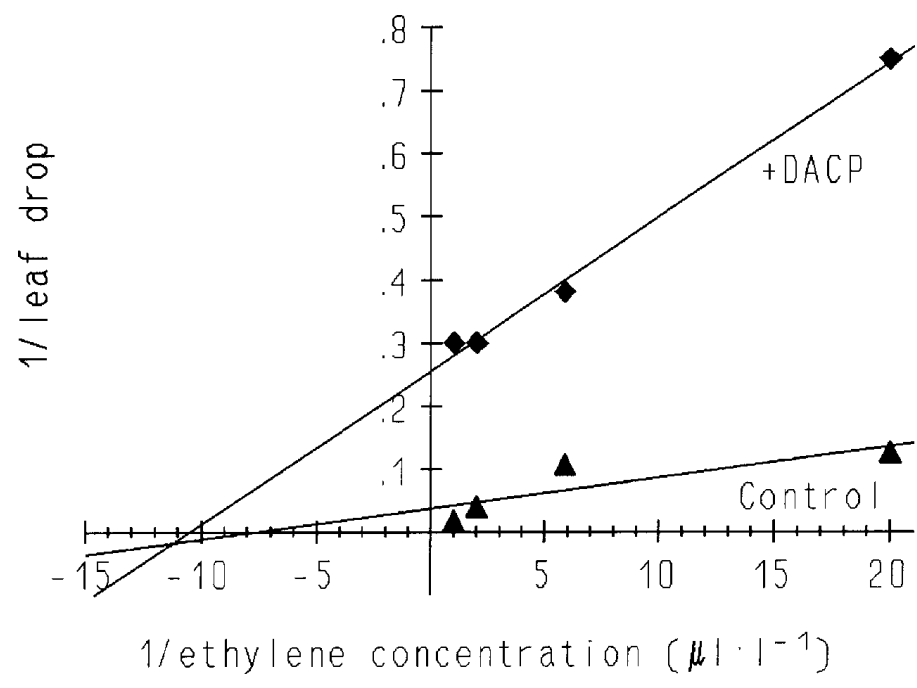

Fig. 7. Double-reciprocal plot of leaf drop of miniature rose 'Victory Parade' plants, with or without a $1 \mu \mathrm{l} \cdot$ liter $^{-1}$ DACP pretreatment, as a function of ethylene concentration.

2,5-Norbornadiene (NBD), a competitive inhibitor of ethylene binding (Sisler et al., 1986) is such a compound, but because binding is competitive, its action requires continued presence of NBD, a toxic and offensive smelling compound. The photoactive DACP molecule was synthesized to provide a compound that would bind at the ethylene binding site and then, by covalently attaching when photoactivated, remain at the site. The effects of this compound on cut carnations and other ethylene-sensitive tissues (Sisler and Blankenship, 1993; Sisler et al., 1993) indicate that it does have the desired effect. The data presented here support the hypothesis that DACP's effectiveness in inhibiting ethylene action is a result of a permanent attachment to the binding site. DACP that has not been irradiated will bind to the receptor in the dark, but the concentration required is much higher than DACP that has been irradiated. The Kds for irradiated DACP are two to eight times higher than those for ethylene. The concentration values reported here are for DACP; however, the active component may be in much lower concentration than the original DACP. Since the active component appears to bind permanently, this likely would be the case. Also it may have a greater binding affinity than DACP. The double-reciprocal plot of the effects of varying ethylene concentrations on leaf drop in control and DACP-treated plants indicates the noncompetitive inhibition that would be anticipated with the covalent obstruction of the binding site that is hypothesized.

Our data are also of intense practical interest, indicating the utility of volatile inhibitors of ethylene action for improving the quality of potted flowering plants, whether by preventing the effects of ethylene encountered during transport and marketing or by extending the life of the plants in the domestic environment. The effect of the inhibitor on binding activity in a cut-flower rose cultivar suggests that volatile ethylene inhibitors could also be useful in preventing the deleterious effects of ethylene in those cultivars that are sensitive (Reid et al., 1991).

It is particularly interesting to note the improvement in bud opening of plants treated with DACP and held in the interior environment. Under the low light conditions typical in homes and offices, bud abortion and abscission are common problems for potted flowering plants. Because the plants are near the photosynthetic light compensation point, they presumably have low carbohydrate reserves. In enchantment lilies (Van Meeteren and De
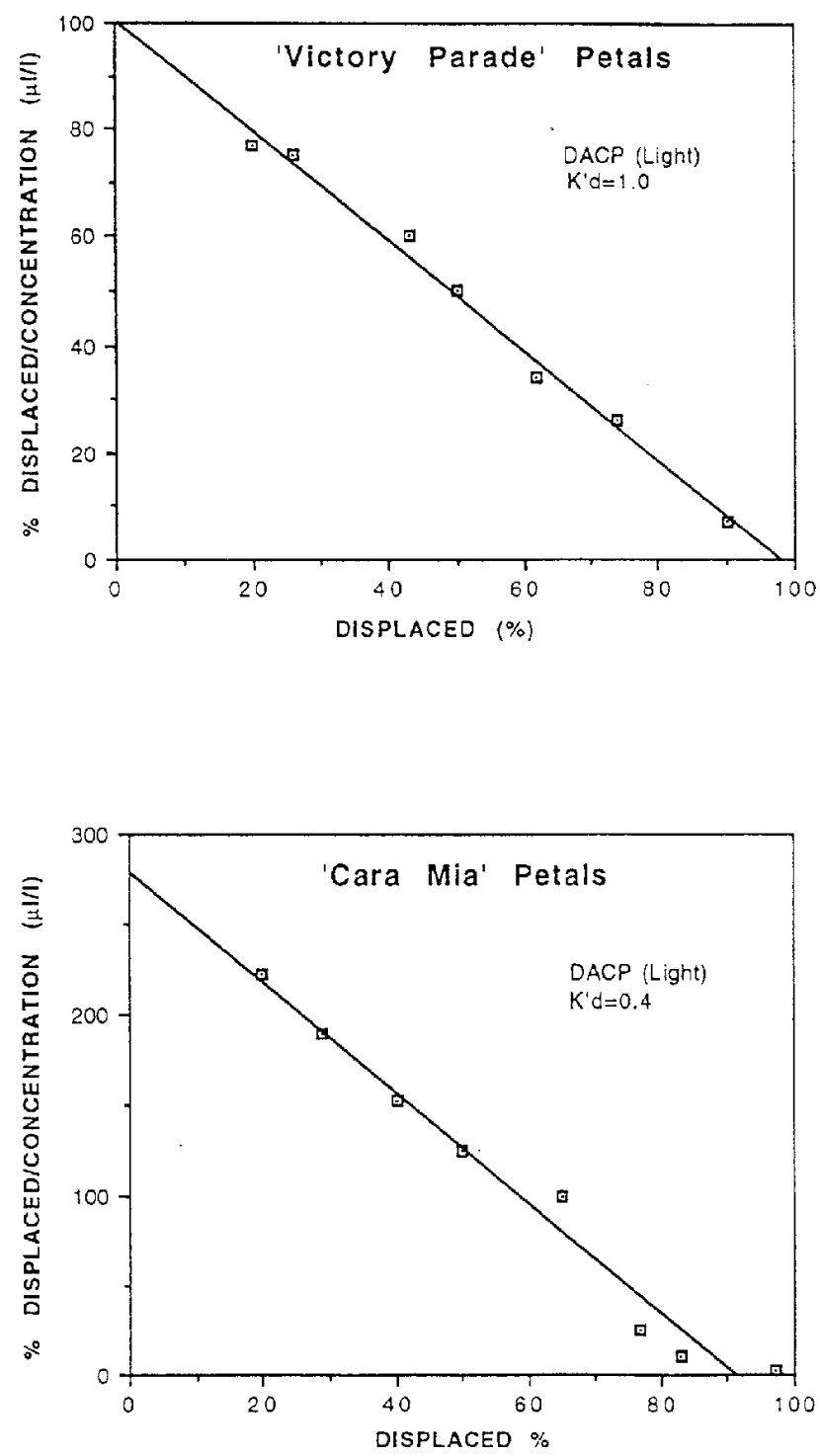

Fig. 8. Scatchard plot of photolysis products of DACP formed in the light. Petals were exposed to the photolysis product for $3 \mathrm{~h}$ in the presence of $14 \mathrm{C}$-ethylene, then vented for $30 \mathrm{sec}$ before collecting the remaining ethylene. The $\mathrm{K}^{\prime} \mathrm{d}$ values obtained here are apparent dissociation constants. See Table 2 for the values corrected for the presence of ethylene $(\mathrm{Kd})$.

Table 2. Binding constants (Kd values) of rose petals and leaves obtained from scatchard plots. The values indicated for DACP in the light represent the photolysis product of DACP after $3 \mathrm{~h}$ in the light. Values have been corrected for the presence of ${ }^{14} \mathrm{C}$-ethylene in the assay (Presecan et al., 1989; Sisler, 1979) using the formula $\mathrm{K}^{\prime} \mathrm{d}=\mathrm{Kd}(1+\mathrm{S} /$ $\mathrm{Ks})$, where $\mathrm{S}$ and $\mathrm{Ks}$ refer to the concentration and dissociation constants for ethylene. The Kd value is the concentration of compound that will occupy one-half of the binding sites in the absence of competing ethylene. The range of concentrations tested was from 0.01 to $100 \mu 1 \cdot$ liter $^{-1}$ (Sisler and Blankenship, 1993).

\begin{tabular}{llrr}
\hline \hline & \multicolumn{1}{c}{ Treatment } & \multicolumn{2}{c}{ Value $\left(\mu 1 \cdot\right.$ liter $\left.^{-1}\right)$} \\
\cline { 3 - 4 } Cultivar & \multicolumn{1}{c}{ Petal } & \multicolumn{1}{c}{ Leaf } \\
\hline Cara Mia & Ethylene & 0.16 & 0.14 \\
Cara Mia & 14C-Ethylene + DACP (light) & 0.34 & 0.39 \\
Cara Mia & 14C-Ethylene + DACP (dark) & 141.00 & 146.00 \\
Victory Parade & Ethylene & 0.12 & 0.11 \\
Victory Parade & 14C-Ethylene + DACP (light) & 0.80 & 0.89 \\
Victory Parade & 14C-Ethylene + DACP (dark) & 208.00 & 200.00 \\
\hline
\end{tabular}


Proft, 1982) and freesias (Spikman, 1989), it has been shown that low carbohydrate content results in accelerated ethylene production and bud abortion. These symptoms were prevented by treating the growing plants or developing cut flowers to inhibit the production or action of ethylene. The striking effect of DACP on flower opening in miniature rose plants presumably has a similar explanation. Certainly buds on plants grown in higher light intensities all develop into open flowers. Reduced carbohydrate content of plants during their display presumably also explains the difference in longevity of flowers that were open at the time of treatment and those that opened in the interior environment (Table 1). The beneficial effects of an anti-ethylene treatment suggest that, in this miniature rose cultivar, ethylene is involved in flower senescence.

\section{Literature Cited}

Halevy, A.H. and A.M. Kofranek. 1976. The prevention of flower bud and leaf abscission in pot roses during simulated transport. J. Amer. Soc. Hort. Sci. 101:658-660.

Nowak, J. and R.M. Rudnicki. 1990. Postharvest handling and storage of cut flowers, florist greens and potted plants. Chapman and Hall, London.

Presecan, E., H. Porumb, and I. Lascu. 1989. Potential misinterpretation of the competitive binding assays. Trends Biochem. Sci. 14:443-444. Reid, M.S. 1985. Ethylene and abscission. HortScience 20:45-50.

Reid, M.S., R.Y. Evans, and L.L. Dodge. 1991. Ethylene and silver thiosulfate influence opening of cut rose flowers. J. Amer. Soc. Hort. Sci. 114:436-440.
Reid, M.S. and M.J. Wu. 1992. Ethylene and flower senescence. Plant Growth Regulat. 11:37-43.

Serek, M. and A.S. Andersen. 1993. Floral development and longevity of miniature potted cultivar 'Victory Parade' under the influence of aminooxyacetic acid (AOA) or benzyladenine (BA). HortScience 28:1039-1040.

Sisler, E.C. 1979. Measurement of ethylene binding in plant tissues. Plant Physiol. 64:538-543.

Sisler, E.C., M.S. Reid, and S.F. Yang. 1986. Effect of antagonists of ethylene action on binding of ethylene in cut carnations. Plant Growth Regulat. 4:213-218.

Sisler, E.C. and S.M. Blankenship. 1993. Diazocyclopentadiene, a light sensitive reagent for the ethylene receptor. Plant Growth Regulat. 12:125-132.

Sisler, E.C., S.M. Blankenship, M. Fearn, C. Jeffrey, and R. Hanes. 1993. Effect of diazocyclopentadiene (DACP) on cut carnations, p. 182-187. In: J.C. Pech, A. Latche, and C. Balaque (eds.). Cellular and molecular aspects of the plant hormone ethylene. Kluwer Academic Publishers, Dordrecht, The Netherlands.

Spikman, G. 1989. Development and ethylene production of buds and florets of cut freesia inflorescences as influenced by silver thiosulfate, aminoethoxyvinylglycine and sucrose. Scientia Hort. 31(1):73-81.

Van Meeteren, U. and M. de Proft. 1982. Inhibition of flower bud abscission and ethylene evolution by light and silver thiosulphate in Lilium. Physiol. Plant. 56:236-240.

Zacarias, L. and M.S. Reid. 1990. Role of growth regulators in the senescence of Arabidopsis thaliana leaves. Physiol. Plant. 80:549-554. 